\title{
The development of accessibility practices in e-learning: an exploration of communities of practice
}

\author{
Jane Seale* \\ University of Southampton, UK
}

The UK's 2001 Special Educational Needs and Disability Act has charged learning technologists with the responsibility of ensuring that electronic teaching materials can be accessed by disabled students. In an attempt to explore how learning technologists are developing practices to produce accessible electronic materials this paper will present a review of the accessibility literature and identify key issues that may influence the 'accessibility' practices of learning technologists. These emerging issues are interpreted using Wenger's theory of communities of practice, with a particular emphasis on the development of accessibility practices that may be shared by a number of related communities of practices and on how the focus of accessibility practices may soon shift from the product to the process of accessibility.

\section{Introduction}

The UK's 2001 Special Educational Needs and Disability Act (SENDA) was brought in as an amendment to the 1995 Disability Discrimination Act (DDA) and is being implemented as Part IV of that Act (HMSO, 1995, 2001). From 1 September 2002, SENDA made it an offence for educational institutions to discriminate against a disabled person by treating him or her less favourably than others for a reason relating to their disability. The Act covers all aspects of student services, but the particular aspects that are relevant to the work of learning technologists include e-learning, distance learning, examinations, assessments and learning resources (including libraries and computer facilities).

Those skilled in interpreting the law have been heavily involved in trying to translate the implications of SENDA 2001 for the learning technology community. For example, as a representative of the JISC Legal Information Service, Wilder (2002, p. 6) advises:

\footnotetext{
*School of Education, University of Southampton, Highfield, Southampton SO17 1BJ, UK. Email: J.K.Seale@soton.ac.uk
} 
The legislation affects the provision of Information Technology and Computing Services in the very widest sense of the phrase and ignoring the legislation is not an option.

On one level her advice is clear: educational institutions cannot avoid responsibility. But with regards to web accessibility, her advice reveals that whilst there is an imperative not to ignore the legislation, how educational institutions attempt to implement the law in practice is likely to vary greatly depending on their understanding and interpretation of what standards the courts will use as benchmarks when judging 'reasonable adjustment'.

Such interpretations of the law suggest a potential tension for learning technologists. One the one hand it is very clear that they must respond to SENDA, but on the other a clearly understood and articulated practice that defines and lays out how the implications of SENDA can be implemented may de difficult to identify.

In an attempt to identify and describe the development or shaping of emerging 'accessibility' practices, Seale (2003) presented a review of literature that focused on learning technologists' interpretation of and response to the legislation. Seale used the concept of communities of practice (Wenger, 1998) to explore and discuss these interpretations and responses and argue that there was evidence that a community of practice was beginning to emerge and that the enterprise of this community was to develop a clearly understood and articulated practice that defines and describes how the implications of SENDA can be implemented. This paper expands and builds on the review of Seale (2003) and explores in greater depth the value of conceiving the accessibility community as a constellation of related communities and the implication this has for our understanding of accessibility practices in e-learning.

\section{A review of accessibility practices in e-learning}

In order to explore what key professionals (academics, researchers, educational developers and staff developers) within the learning technology field in the UK were saying and doing about making electronic materials and resources accessible to disabled students a review was undertaken of literature published between January 2000 and September 2003. In order to encompass the experiences of both researchers and practitioners the review covered academic and professional literature and included journal articles, books, newsletter articles and web-based materials. The review was also limited to material that focused on UK based accessibility initiatives and practices.

This review revealed four key issues that may influence the 'accessibility' practices of learning technologists in the UK:

- the difficulties of responding to SENDA;

- the identification and implementation of existing accessibility tools and guidelines in order to comply with SENDA;

- the adaptation or re-framing of generic accessibility tools and guidelines for more specific practice(s);

- a call to involve disabled people or their advocates in the design of electronic material.

Seale (2003) reports these issues in detail; a summary is provided here. 


\section{The difficulties of responding to SENDA}

The DDA 1995 has been described as an example of an "increasingly complex and encroaching legislation, which tends to creep up on the unsuspecting manager of an HEI" (Palfreyman \& Warner, 2002, p. 423). These sentiments of sympathy for senior managers continue in the current discussion of the legal imperatives of SENDA and are coupled with a perception that higher educational institutions will find it difficult to respond to SENDA (see, for example, Wilson et al., 2002).

The difficulties in responding to SENDA are also expressed in terms of how individuals will have to learn a lot of new information very quickly when attempting to design or develop new accessible materials (Ormerod, 2002; Witt \& McDermott, 2002).

The identification and implementation of existing accessibility tools and guidelines in order to comply with SENDA

A number of accessibility guidelines were in existence prior to SENDA and a review of the literature reveals a large number of articles that attempt to suggest how they could be used to help comply with the act. The most commonly cited guidelines are those that focus on web accessibility, for example those produced by the world wide web consortium (WC3), most specifically the web content accessibility guidelines (WCAG). These outline three priority levels and the general consensus seems to be to design for priority 1 and 2 (McCarthy, 2002).

The experience of Witt and McDermott (2002) led them to report how they needed to produce their own simplified version of the WCAG because 'extracting the desired information can be confusing'. Some simplified guidelines do however, appear to rather over-simplified. For example, the 'accessibility golden rules' of Sloan et al. (2000) includes the rather vague rule, 'use valid HTML and follow the Web Content Accessibility Guidelines'. The existence of overly simple or overly complicated guidelines lead Jeffels and Marston (2003) to argue for guides that are directly relevant to learning technology developers and which are closely linked to or embedded in practical and local issues where appropriate.

The adaptation or re-framing of generic accessibility tools and guidelines for more specific practice(s)

Attempts to create more meaningful and relevant interpretations of guidelines have resulted in two distinct practices. The first practice focuses on the production of technology specific guidelines (Pearson \& Koppi, 2001; Sloan et al., 2003; Smith, 2002; Stiles, 2001). For example, Pearson and Koppi (2001) evaluated the accessibility of WebCT in practice at University of New South Wales and distilled their findings into a set of guidelines for academic designers of WebCT courses.

The second practice focuses on the production disability specific guidelines. For example Blankfield (2002), Lockley (2002) and Rainger (2003) give some advice on 
making web based course materials accessible to dyslexic students. Whilst Lockley offers five simple design guidelines, there is no indication of whether these guidelines are grounded in practice and experience. Blankfield on the other hand based what she calls 'good practice' guidelines on interviews that she had conducted with dyslexic students who were using WebCT, whilst Rainger indicates that his guide is derived from 'practitioner's experience and usability research'.

\section{A call to involve disabled people or their advocates in the design of electronic material}

Pearson and Koppi (2001) argue that the key to accessible courseware is to take a learner-centred design approach, while Smith (2002) emphasises the involvement of dyslexic students in his design of a Virtual Learning Environment Interface and makes a plea for a wider deployment of user testing.

In addition to the call to involve disabled students there is a call to engage in a dialogue with people who are knowledgeable about the needs and concerns of students with disabilities (Conroy 2002; Middling \& Bostock, 2002; Phipps, 2002). For example, Phipps (2002) urges staff and educational developers to give serious consideration to using 'non-traditional facilitators' such as disability officers for workshops in this field.

\section{A framework for exploring the enterprise of accessibility}

The Disability Discrimination Legislation has charged learning technologists with the responsibility of developing accessible electronic teaching material and resources. Using concepts from Wenger's (1998) Communities of Practice framework, learning technologists could be viewed as needing to pursue an 'enterprise' of accessibility. The issues drawn out from a review of the literature could therefore be interpreted as representing learning technologists attempts to define this enterprise and start to collectively describe practices that reflect the pursuit of this enterprise.

In an attempt to further explore and understand this enterprise and its resulting practices the results of the literature review will be interpreted using Wenger's concept of 'practice', which is understood as:

- giving structure and meaning to what communities do;

- being a source of coherence for a community; and

- having boundaries and peripheries that may link with other communities.

\section{A practice that gives structure and meaning to what learning technologists do}

According to Wenger, practice is about 'meaning as an experience of everyday life'. He argues that what is important about the pursuit of enterprises is the meanings that are produced from these pursuits. Meaning is located in a process he termed 'negotiation of meaning', which involves the interaction of two processes: participation and reification. If participation in communities shapes our experience through 
membership and active engagement, reification gives form to our experience by producing objects that 'congeal this experience into thingness'.

Reification creates points of focus around which the negotiation of meaning becomes organised. So for example reification produce a range of laws, procedures or tools. The negotiation of meaning, therefore, may become focused around using a law to argue a point, using a procedure to know what to do or using a tool to perform an action. The findings from the literature review might suggest that in the pursuit of an accessibility enterprise, the negotiation of meaning for the learning technology community may currently be focused more on reification than participation. The literature is dominated by the description and discussion of laws (e.g. SENDA, 2001), procedures (e.g. WCAG) and tools (e.g. the LIFT plug-in). The ultimate artefacts of practices that learning technologists might develop in the pursuit of an accessibility enterprise would be actual accessible electronic learning materials. However, the literature pointed to very few examples of these (Smith, 2002; Witt \& McDermott, 2002).

Wenger recognised that a very large portion of reification involved in work practices can come from outside communities. In this case he argues reification must be re-appropriated into a local process in order to become meaningful. The findings from the literature review present some evidence for re-appropriation. As example of this is the re-framing and adaptation of general accessibility guidelines (WCAG) that have been associated with national laws (SENDA) to suit local or more specific needs (Blankfield, 2002; Lockley, 2002; Pearson \& Koppi, 2001; Rainger, 2003; Sloan et al., 2000).

Wenger talks of the 'double edge of reification' and states that a good tool can reify an activity so as to amplify its effects while making the activity effortless. A bad tool, therefore, can 'ossify activities around its inertness'. From the literature review there is some evidence that learning technologists would recognise this phenomena, for example, those who point to the inappropriate use of the Bobby logo on web sites (Phipps et al., 2002; Witt \& McDermott, 2002).

The Bobby logo displayed a statement of the values of accessibility and had become something that people could point to and strive for. Yet as a reification it did not capture the richness of what is understood by accessibility because it could be appropriated in misleading ways. It could therefore become a false representation of what it was intended to reflect. In some part the learning technology community has recognised this in its move away from Bobby and towards WCAG (McCarthy, 2002; Wilder, 2002; Witt \& McDermott, 2002).

Wenger warns that if reification prevails over participation, if everything is reified but with little opportunity for shared experience and interactive negotiation, then there may not be enough overlap in participation to recover a co-ordinated, generative meaning. The learning technology community may certainly be in danger of this. Findings from the literature review would suggest a prevalence of laws, guidelines and tools. For example, Witt and McDermott (2002) report that a recent audit of accessibility software identified 30 site-evaluation tools, 10 web page repair tools and over 20 filter and transformation tools. 
Practice that is a source of coherence for the learning technology community

Wenger describes three dimensions by which practice is a source of coherence for a community: mutual engagement, joint enterprise and shared repertoire. In defining mutual engagement Wenger states that practice exists because people are engaged in actions whose meanings they negotiate with one another. What makes a community of practice out of a medley of people is their mutual engagement as they make things happen. In the learning technology community we certainly have a medley of people (disability officers, academics, researchers, staff developers, etc.); the literature review produced some examples of how these different people are attempting to work together to develop 'accessible' online learning material (e.g. Conroy, 2002; Middling \& Bostock, 2002).

In defining and discussing the concept of joint enterprise, Wenger introduces the notion of 'indigenous enterprise' and argues that conditions, resources and demands will only shape practice if the community has negotiated that. To exemplify this, Wenger gives an example of a community of practice that has arisen in response to some outside mandate and argues that practice evolves into the community's own response to that mandate. This example has some resonance for the learning technology community who might perhaps see SENDA as an outside mandate that has been imposed on the community. If we accept the findings of the literature review as evidence that members of the community are attempting to produce a practice to deal with what they understand to be their enterprise, their practice as it unfolds will belong to the community, even though external drivers such as SENDA may have prompted it.

\section{Practice that has boundaries and peripheries that may link with other communities}

According to Wenger, communities of practice cannot be considered independently of other practices. Their various enterprises are closely interconnected, their members and their artefacts are not theirs alone. Communities of practice are therefore sources of boundary and contexts for creating connections. Wenger presents two kinds of connections: boundary objects and brokering. Boundary objects are defined as artefacts, documents, terms, concepts, and other forms of reification around which communities of practice can organize their interconnections. Brokering is described as the connections provided by people who can introduce elements of one practice into another.

\section{Connection one: boundary objects}

Artefacts such as SENDA and WCAG could be viewed as boundary objects in the sense that multiple constituencies refer to them in the literature when trying to negotiate or define theirs and others practice, e.g.:

- academics (Blankfield, 2002; Conroy, 2002; Ormerod, 2002);

- staff developers (Middling \& Bostock, 2002); 
- researchers (Wilson et al., 2002);

- technicians/technologists (Smith, 2002; Witt \& McDermott, 2002).

Wenger notes that the design of artefacts (documents, systems, tools) is often the design of boundary objects. He illustrated this by giving an example of designers of computer systems, who focus on issues of use and often employ the term 'the user' as a generic term with 'mythical proportions'. From this perspective, 'use' is a relation between a user and an artefact. However, that user engages in certain practices and is therefore a member of certain communities of practice. Artefacts can therefore be boundary objects, and designing them might involve designing for participation rather than just use. Designing accessible e-learning material may therefore involve designing boundary objects in the sense that that may enable users (students with disabilities) to engage in practices that enable them to participate in a number of communities, including learning communities.

\section{Connection two: brokers}

Wenger argued that when people transfer from one community of practice to another, or have multi-membership, they can transfer some element of one practice into another through 'brokering'. Brokers are able to make new connections across communities of practice, enable coordination, and open new possibilities for meaning. This notion of brokers who can create connections between communities is reflected in the literature that discusses the role of staff developers. For example, Middling and Bostock (2002) describe how in response to SENDA legislation their institution has begun to develop staff development programmes jointly between Disability Services, Staff Development teams and departments, while Phipps (2002) argues that developers must act in a brokerage role with all staff providing perspectives that can inform strategic policy and decisions. An example of this brokerage role in action might be the collaboration of the Higher Education Staff Development Agency with the Disability Rights Commission, The National Bureau for Students with Disabilities, Universities UK, Universities Scotland, Higher Education Wales and Scottish Higher Education Funding Council to produce a Staff Development Good Practice Guide. ${ }^{1}$ In addition, the call to involve the advocates of disabled students in the design of electronic material (Conroy, 2002) might place disability officers in the role of broker.

According to Wenger, the job of brokering is a complex one. It involves processes of translation, co-ordination and alignment between perspectives. Brokers need to:

- have legitimacy so that they can influence the development of practice;

- be able to link practices by facilitating transaction between them; and

- be secure in living on the boundaries of practices.

The literature review revealed a call to involve advocates of students with disabilities in the design of accessible electronic material. Disability officers are commonly cited as one such advocate. However, there is some evidence to suggest that Disability 
Officers as a whole group may not be secure enough in their own identity to fulfil this brokerage role at the moment. For example, an inspection of the National Association of Disability Officers (NADO) website ${ }^{2}$ reveals that a fair number of the discussion papers and conference abstracts seem to focus on the issue of 'professional identity and development' and the difficulties of trying to span different communities.

Some individual disability officers may be secure enough to live on boundaries of practices. Draffen, for example, is a member of NADO and also works for TechDis, a JISC funded service that aims to be the primary source of information and advice for institutions on the use of ICT to support students and staff with Learning Difficulties and/or Disabilities. In her TechDis role Draffan manages an accessibility database that provides an on-line resource of information about assistive, adaptive and enabling technologies for the UK post-16 education sector. She has also published a number of articles on issues of accessibility and discrimination (e.g. Draffen, 2002).

\section{A constellation of practices}

A further implication of the identification of boundary objects, brokers and boundary practices within the learning technology literature is that in searching for an enterprise of accessibility, the review may not have identified one community of practice but rather a constellation of practices. The term constellation refers to a grouping of stellar objects that are seen as a configuration even though they may not be particularly close to one another, of the same kind, or of the same size. Wenger explains that there are many different reasons that some communities of practice may be seen as forming a constellation. These include having related enterprises, facing similar conditions, having members in common and sharing artefacts.

In her original review of the literature, Seale (2003) argued that four different communities or constituencies fall under the broad term 'learning technology community' and therefore form a constellation. She defined these communities as:

- designers of accessible electronic material: e.g. lecturers, educational developers, and technical support staff;

- users of accessible electronic material: students with disabilities;

- advocates for students with disabilities: e.g. disability officers or co-ordinators; and

- disseminators of information about best accessible design practice: e.g. staff developers.

In defining these communities Seale (2003) argued that all four had a related enterprise, that of 'accessibility'; that each faces similar conditions in that they all operate in the post-compulsory education environment; that each may have members in common (e.g. a disability officer could also be involved in staff development); and that each shares artefacts such as SENDA and WCAG. Seale (2003) went on to highlight the potential growth of 'boundary practices' that will link these communities in some way So, for example, the call for the involvement of users in the design of accessible electronic material suggests a boundary practice for which advocates could 
be brokers. The call for the involvement of advocates in dissemination of information about good or best practices suggests a boundary practice for which staff developers may be brokers.

\section{Exploring related communities of practice}

Other communities of practice, besides those identified in this review, have also been concerned with accessibility. Most notably, these include the assistive technology (AT) and human-computer interaction (HCI) communities (Akoumianakis \& Stephanidis, 2003). The assistive technology community focuses on the design, production and evaluation of equipment (including software) that can be used to maintain or improve the functional capabilities of people with disabilities (Banes \& Seale, 2002), whilst the HCI community focuses on the design, evaluation and implementation of interactive computing systems for human use (Baecker et al., 1995). These communities have longer individual histories than the learning technology community but also have a history of sharing ideas, theories and models in order to address access and accessibility issues. It may be therefore helpful for these communities to share elements of their tradition and practice with the learning technology community.

One factor that has drawn the assistive technology and human-computer interaction communities together has been their shared interest in the principles of universal design. Products designed using the principles of universal design:

- are developed with consideration of the needs of a diverse population;

- are not described as being anything more than easy for everyone to use;

- are always accessible (but because accessibility has been integrated from the beginning of the design process, they are less likely to be noticeable); and

- benefit everyone, not only disabled people (Banes \& Seale, 2002).

\section{Assistive technology and universal design}

In defining its practice, the assistive technology community distinguishes between accessible design, adaptable design and universal design (Story, 1998). Accessible design meets prescribed code requirements for use by people with disabilities but is often achieved by providing separate design features for 'special' user groups. Adaptable design involves making modifications to a standard design for the purpose of making the design usable for an individual, as needed. Universal design is the design of products and environments that can be used and experienced by people of all abilities, to the greatest extent possible, without adaptation.

Story (1998) argues that universal designs are developed with consideration for the needs of a diverse population and therefore do not call attention to themselves as being anything more than easy for everyone to use. Universal designs are always accessible but because they integrate accessibility from the beginning of the design process, they are less likely to be noticeable (and hence stigmatising). However, 
universal designs may sometimes employ adaptable strategies for achieving customisation. For these reasons, Story (198) argues that universal designs are the most inclusive and least stigmatising of the three types of design. Building on these arguments, Iwarsson and Stahl (2003) argue that accessible design is based on the assumption that designers have to design for two populations: the normal population and the abnormal population (people with disabilities). In contrast, universal design is based on the assumption that there is 'only one population comprised of individuals representing diverse characteristics and abilities. Accessible design can therefore be stigmatising, whereas universal design can be equalising.

\section{Human-computer interaction and universal accessibility}

The HCI community has embraced universal design to the extent that it has examined its assumptions about the populations it designs for and in doing so adopted a principle that has been termed 'universal accessibility' or 'universal usability'. In exploring this principle, Stephanidis et al. $(1998$, p. 1) argued that the principle of designing for the 'average' user would be gradually replaced by the "more demanding and challenging objective of designing to cope with diversity". They go on to suggest that in seeking to understand in more detail the needs of people with disabilities a new understanding of human interaction will emerge, which will lead to a new generation of products that "will be improved in their usability, will be intuitive to use and will be accessible by the broadest possible end-user population" (Stephanidis et al., 1998, p. 2).

In discussing the impact on the HCI community of the shift in focus to designing for diverse populations, Akoumianakis and Stephanidis (2003, p. 228) outline the nature of the challenge and conclude:

It becomes compelling that designers' conception of users should (somehow) accommodate the requirements of as broad a range as possible, or ultimately all potential citizens, including the young and the elderly, residential users, as well as those with situational or permanent disability.

\section{Learning technology and universal design}

Some learning technologists, when discussing how to cater for the individual needs of disabled students, argue strongly for what they call 'design for each' and reject suggestions that in trying to design for all students the needs of disabled students will, for the most part, be catered for. Such rejections demonstrate a lack of understanding of universal design (design for all) principles and suggest that they would benefit from engaging with the AT and HCI communities, which have drawn heavily on these principles in developing their own design practices. By doing so, learning technologists may be able to develop what Scott et al. (2003) call an 'integrative approach' where the focus is shifted away from making exceptions for different learners to anticipating and planning for student diversity as the norm. 


\section{Discussion: towards a rounder practice?}

An exploration of current practice suggests that learning technologists are perhaps overly focused on the product of accessibility practices (e-learning materials and resources) rather than the process by which they are produced. There is some evidence to suggest however that the focus is gradually shifting from describing or defining the attributes of the end-product (e.g. the accessible web site) towards describing the process by which these products are developed. To use Wengers' terms, this represents a shift from reification to participation.

Virtual Learning Environments (VLEs) offer a useful illustration of this. Since we now have guidelines for designing accessible VLEs (Pearson \& Koppi, 2001) and tools for designing VLE interfaces (Smith, 2002) we can perhaps move towards describing different ways of using VLEs with disabled students (Bradley \& Woodford, 2003) as well as exploring different pedagogical approaches to supporting disabled students in their use of VLEs (e.g. the ALERT project ${ }^{3}$ ). Such descriptions may contribute to a rounder, fuller picture of accessibility practices. This would enable us to define indicators for accessible practices as well as for accessible elearning materials. Such indicators could then be used to develop an 'Index of Accessibility', comparable to the Index for Inclusion produced by the Inclusive Education Community (Booth \& Ainscow, 2000). The index for inclusion is a resource or tool that invites schools to identify barriers to learning and participation and invites them to reduce those barriers by addressing cultures, policies and practices (Vaughn, 2002). The review and analysis of accessibility practices in Higher Education in the UK suggests that there may be value in identifying barriers to the design and implementation of accessible electronic materials (e.g. lack of user involvement) and exploring how changes or adaptations to cultures, policies or practices might reduce these barriers.

\section{Conclusion}

The application of Wenger's (1998) theory to the development of accessible e-learning has facilitated an exploration of current practice which suggests that the learning technology community might be attempting to develop a practice to deal with what they understand to the their 'enterprise' and to own that practice despite the perceived imposition of laws such as SENDA. The interpretation of Wenger's concept of communities of practice as it relates to current e-learning "accessibility practices" in Higher Education also suggests some recommendations for the future development of these practice:

1. It may be helpful for the learning technology community to make links with other related communities in order to identify related practices and explore the extent to which these practices may influence the focus or nature of its own practice.

2. At some point in the near future, the learning technology community might also benefit from shifting its attention away from the product of accessibility towards the process of accessibility. 
Engagement with the principles of universal design would be one way of advancing practice in line with both of these recommendations.

\section{Acknowledgements}

This paper is based on a research paper presented at $A L T-C 2003$ and published in the conference's research proceedings.

\section{Notes}

1. http://www.drc-gb.org/drc/Documents/staff $\% 20$ development.doc

2. http://www.nado.ac.uk/

3. www.dur.ac.uk/lt.team/alert

\section{References}

Akoumianakis, D. \& Stephanidis, C. (2003) Blending scenarios of use and informal argumentation to facilitate universal access: experience with the Universal Access Assessment Workshop method, Behaviour and Information Technology, 22(4), 227-244.

Baecker, R., Grudin, J., Buxton, W., Greenberg, S. (Eds) (1995) Readings in human-computer interaction: towards the year 2000 (Los Altos, CA, Morgan-Kaufmann).

Banes, D. \& Seale, J. (2002) Accessibility and inclusivity in further and higher education: an overview, in: L. Phipps, A. Sutherland \& J. Seale (Eds) Access all areas: disability, technology and learning (Oxford and York, ALT/TechDis), 1-5.

Blankfield, S. (2002) Supporting dyslexic students in effective use of online learning, paper presented at Association for Learning Technology Conference, Sunderland, 2002. Available online: http://www.alt-c2002.org.uk/ (accessed 22 November 2003).

Booth, T. \& Ainscow, M. (2000) Breaking down the barriers: the Index for Inclusion. Available online: http://inclusion.uwe.ac.uk/csie/index-inclusion-summary.htm (accessed 22 November 2003).

Bradley, S. \& Woodford, R. (2003) Support for dyslexic students within the virtual learning environment, paper presented at Association for Learning Technology Conference, Sheffield 2003. Abstract available online: http://www.shef.ac.uk/alt/postconf/papers/all/index.htm (accessed 22 November 2003).

Conroy, G. (2002) Delivering an inclusive curriculum using specialist software. Available online: http://www.hefce.ac.uk/pubs/hefce/2002/02-5F48/02\%5F48c3.pdf (accessed 22 November 2003).

Draffen, E. (2002) Dyslexia and technology, in: L. Phipps, A. Sutherland \& J. Seale (Eds) Access all areas: disability, technology and learning (Oxford and York, ALT/TechDis), 24-48.

HMSO (1995) Disability Discrimination Act. Available online: http://www.legislation.hmso.gov.uk/ acts/acts1995/Ukpga_19950050_en_1.htm (accessed 22 November 2003).

HMSO (2001) The Special Educational Needs and Disability Act. Available online: http://www.legislation.hmso.gov.uk/acts/acts2001/20010010.htm (accessed 22 November 2003).

Iwarsson, S. \& Stahl, A. (2003) Accessibility, usability and universal design — positioning and definition of concepts describing person-environment relationships, Disability and Rehabilitation, 25(2), 57-66.

Jeffels, P. \& Martson, P. (2003) Accessibility of online learning materials. Available online: www.scrolla.hw.ac.uk/papers/ (accessed 22 November 2003).

Lockley, S. (2002) Dyslexia and higher education: accessibility issues. Article on ILT members' area of the ILT website: www.ilt.ac.uk (accessed 22 November 2003). 
McCarthy, D. (2002) Disability legislation and accessibility of online materials. Article on ILT members' area of the ILT website: www.ilt.ac.uk (accessed 22 November 2003).

Middling, T. \& Bostock, S. (2002) Accessibility: implications for teaching staff and staff developers, Educational Developments, 3(3), 8-9.

Ormerod, M. (2002) Developing an accessible distance taught MSc. Available online: http:// www.hefce.ac.uk/pubs/hefce/2002/02\%5F48/02\%5F48c3.pdf (accessed 22 November 2003).

Palfreyman, D., Warner, D. (Eds) (2002) Higher Education Law (Bristol, Jordans).

Pearson, E. \& Koppi, T. (2001) Inclusion and online learning opportunities: designing for accessibility, Association for Learning Technology fournal, 10(2), 17-28.

Phipps, L., Witt, N. \& McDermott, A. (2002) To logo or not to logo? Available online: http:// www.techdis.ac.uk/resources/logo001.html (accessed 22 November 2003).

Phipps, L. (2002) Are you reasonably adjusted? Educational Developments 3(4), 6.

Rainger, P. (2003) A dyslexic perspective on e-content accessibility. Available online: http://www.techdis.ac.uk/seven/papers/dyslexia-index.html (accessed 22 November 2003).

Scott, S., McGuire, J. \& Foley, T. (2003) Universal design for instruction: a framework for anticipating and responding to disability and other diverse learning needs in the college classroom, Equity E Excellence in Education, 36(1), 40-49.

Seale, J. (2003) In search of an enterprise of accessibility: communities, practices, boundaries and constellations, in: J. Cook \& D. McConnell (Eds) Research Proceedings of the $10^{\text {th }}$ Association for Learning Technology Conference (Oxford, Association for Learning Technology), 299-313.

Sloan, D. (2002) Creating accessible e-learning content, in: L. Phipps, A. Sutherland \& J. Seale (Eds.) Access all areas: disability, technology and learning (Oxford and York, ALT/TechDis), 35-41.

Sloan, D., Rowan, M., Booth, P. \& Gregor, P. (2000) Ensuring the provision of accessible digital resources, fournal of Educational Media, 25(3), 203-216.

Sloan, D., Stratford, J. \& Stone, S. (2003) Skills for access-accessible multimedia by designers for designers, paper presented at Association for Learning Technology Conference, Sheffield 2003. Available online: http://www.shef.ac.uk/alt/postconf/papers/all/index.htm (accessed 22 November 2003).

Smith, S. (2002) Dyslexia and virtual learning environment interfaces, in: L. Phipps, A. Sutherland \& J. Seale (Eds) Access all areas: disability, technology and learning (Oxford and York, ALT/TechDis), 50-53.

Stephanidis, C., Paramythis, A., Akoumianakis, D. \& Sfyrakis, M. (1998) Self-adapting webbased systems: towards universal accessibility, in: C. Stephanidis \& A. Waern (Eds) Proceedings of the 4th ERCIM Workshop User Interfaces for All, (Stockholm, ERCIM) 19-21.

Stiles, M. (2001) Disability access to virtual learning environments. Digital media access group/ DISINHE. Available online: http://www.dmag.org.uk/resources/casestudies/stilesfull.asp (accessed 22 November 2003).

Story, M. (1998) Maximising usability: the principles of universal design, Assistive Technology fournal, 10(1), 4-12.

Vaughn, M. (2002) An index for inclusion, European fournal of Special Needs Education, 17(2), 197-201.

Wenger, E. (1998) Communities of practice: learning, meaning and identity (Cambridge, Cambridge University Press).

Wilder, B. (2002) Disability legislation: implications for learning technologists in the UK, in: L. Phipps, A. Sutherland \& J. Seale (Eds) Access all areas: disability, technology and learning (Oxford and York, ALT/TechDis), 6-9.

Wilson, A., Ridell, S. \& Tinklin, T. (2002) Disabled students in Higher Education. Available online: http://www.ed.ac.uk/ces/Disability/index.htm (accessed 22 November 2003).

Witt, N. \& McDermott, A. (2002) Achieving SENDA-compliance for websites in further and higher education: an art or a science? In: L. Phipps, A. Sutherland \& J. Seale (Eds) Access all areas: disability, technology and learning (Oxford and York, ALT/TechDis), 42-49. 